\title{
IDENTIDADE E BIOGRAFIA
}

Identity and Biography

Sheyla Villar Fredenhagem ${ }^{1}$

RESUMO: O presente texto relata três situações de ensino, cuja realização se deu em momentos distintos, na década de 80, durante as aulas de Literatura e Redação de Cursos Técnicos. Essas experiências foram planejadas com o intuito de oportunizar o estudo do contexto histórico, de compor e de observar uma personagem, de exercitar o autoconhecimento, de favorecer estudo teórico e prático da narração, de desmistificar o ato de escrever e, também, de conhecer melhor os alunos. De forma comum, as atividades tiveram como fio condutor a história de vida, observada em três vertentes: de escritores, de personagens e dos próprios alunos. Sob um olhar a posteriori, este relato propõe reflexões que considerem o pressuposto de que a história de vida responde, de maneira acentuada, pela estrutura basilar da identidade e pela direção de escolhas.

Palavras-Chave: história de vida; biografia; vivências; identidade; referência identitária.

ABSTRACT: This paper reports three cases of teaching, which took place at different times in the 80s during the classes of Literature and Technical Writing Courses. These experiments were designed to provide the opportunity for the study of historical context, creating and observing a character, to exercise self-knowledge, to promote theoretical and practical study of the narrative, to demystify the act of writing, and also to better understand students. In general, the activities were guided by the history of life, observed in three areas: the writers, the characters and the students themselves. Under a retrospective look, this report proposes reflections that consider the assumption that the history of life responds sharply to the basic structure of the identity and direction of choices.

Keywords: life history, biography, experiences, identity, identity reference.

\footnotetext{
${ }^{1}$ Instituto Federal de Educação, Ciência e Tecnologia de Brasília, sheyla.fredenhagem@ifb.edu.br
} 


\title{
Introdução
}

Não há como dissociar identidade de biografia.

Vale lembrar trabalhos que desenvolvi como professora, nas aulas de Literatura e Redação, com alunos do então Curso Técnico de segundo grau, na década de 80 , com o intuito de oportunizar o estudo do contexto histórico, de compor e de observar uma personagem, de exercitar o autoconhecimento, de favorecer estudo teórico e prático da narração, de desmistificar o ato de escrever e, também, de conhecer melhor os alunos. A proposta atendia a esses objetivos delineados previamente, porém, no decorrer das atividades, deparamo-nos com respostas a questões peculiares do universo da atividade docente, antes não pensadas.

As atividades, que tinham como ponto de partida a valorização da biografia, consolidaram-se como exercícios de análise da construção da identidade e/ou de percepção de seus ditames, do ponto de vista de três vertentes: uma das experiências desenvolveuse sob a ótica da história de vida dos escritores, outra sob a ótica da história de vida das personagens, e uma terceira, dos próprios alunos.

As três experiências marcaram, notadamente, minha trajetória como professora, no despertamento sobre a realidade da existência de um processo individual de amadurecimento. Cada vez que eu revolvo essas lembranças, logo me chega à mente o conhecido pensamento do médico e alquimista suíço Paracelso (1493-1541), texto que suscita, em mim, reflexões sobre quão particular é esse processo em cada pessoa e quão importante é o ato de observar e de favorecer momentos de reflexão sobre si mesmo, tanto para 0 professor, quanto para o aluno, em sala de aula.

\begin{abstract}
Quem nada conhece, nada ama. Quem nada pode fazer, nada compreende. Quem nada compreende, nada vale. Mas quem compreende também ama, observa, vê... Quanto mais conhecimento houver inerente numa coisa, tanto maior o amor...Aquele que imagina que todos os frutos amadurecem ao mesmo tempo, como as cerejas, nada sabe a respeito das uvas.
\end{abstract}

\section{Primeira Experiência - História de vida dos escritores}

Em relação à composição do primeiro trabalho que será relatado, como representação da primeira vertente mencionada, o que me influenciou sobremaneira foi a leitura do livro "Essa escola 
chamada vida", que trata de uma entrevista que Paulo Freire e Frei Betto concederam ao repórter Ricardo Kotscho, em 1984, cujo foco temático é a educação popular. Das experiências relatadas no livro, muito chamou a minha atenção o caminho que Frei Betto (2003, p. 83) trilhou, utilizando-se das biografias pessoais como chave do curso que ministrou a trabalhadores. A essas expressões textuais acrescenta: "Eles têm as chaves. As condições sociais: passado, presente e futuro".

Betto (2003, p. 84) em outro trecho afirma:

...dividi a lousa em passado, presente e futuro e fui fazendo um quadro comparativo entre as várias histórias e, no fim, escrevi o nome Brasil. No quadro comparativo, a cronologia deles e a cronologia da história recente do Brasil. (...)Assim, o sujeito vai ligando a sua história pessoal com a história coletiva do povo brasileiro.

Inspirada pela metodologia do aprender na pele (BETTO, 2003), no dizer do autor, orientei os alunos a estudarem a biografia de autores diversos, na perspectiva de descobrirem algumas características em suas obras que pudessem ser justificadas pela vivência dos escritores, ou seja, a fim de que buscassem indícios da história de vida dos autores em obras de sua autoria. Desejava que aprendessem a lidar com o contexto histórico em suas análises, que observassem o período em que o escritor viveu, dados familiares, referências da educação recebida, e que conseguissem identificar essas características nos feitos, nas obras do autor. Esforçava-me para fazer do estudo da biografia objeto da compreensão, não simplesmente da memória. Esta subsidiaria aquela. Enfim, que fosse atribuído um sentido aos dados, ou que descobrissem um sentido nos dados biográficos dentro das obras.

Saíram deduções muito interessantes da parte dos alunos, após estudos da biografia de um determinado autor e leitura de respectiva obra. Uma aluna chegou a associar o conteúdo da crônica "O sonho do feijão", cujo enfoque eram as filas ocasionadas pela falta de produtos disponíveis nas prateleiras, decorrente da alta inflação daquele momento, com o fato de o autor, Carlos Eduardo Novaes, ter percebido sua vocação para escritor somente a partir dos 29 anos, quando ganhou uma máquina de escrever, depois de ter tentado ser ator, funcionário público, agente rodoviário, dedetizador, fabricante de sorvete. Enfim, associou a fila com a espera do escritor até que conseguisse dar um rumo à sua vida. Esperar era um marco comum na vida do autor. Se os alunos concluíram acertadamente a respeito das histórias de vida dos autores as quais justificavam trechos ou 
fatos narrados nas obras, não posso afirmar, porém foi um excelente exercício de reflexão sobre a importância do contexto e do estudo biográfico.

\section{Segunda Experiência - História de vida das personagens}

O segundo trabalho de Literatura desenvolvido em sala de aula diz respeito a um estudo pormenorizado de cada personagem - seria, portanto, a representação da segunda vertente. Chamávamos de "incorporação das personagens". Os alunos liam os livros e escolhiam uma personagem que incorporariam, procurando ler o "universo" da história do livro pela ótica dessa personagem. Antes faziam um estudo atento da personalidade e história de vida da personagem. Em seguida escreviam um texto comentando e analisando fatos do livro, bisbilhotando a vida de outras personagens, sob a ótica da personagem escolhida (incorporada). Como veria tal fato? Como reagiria? Como via as demais personagens? O que pensava a respeito disso ou daquilo? Quais os valores que professava? Como era o seu temperamento? E por aí afora. Sempre com referência ao conteúdo da obra. Tratava-se também de um exercício para aprenderem a compor uma personagem.

Tive duas surpresas nesse trabalho. Uma foi com a inigmática personagem Capitu, de Machado de Assis. A Capitu da aluna era uma adúltera confessa. Dizia não suportar a ranzinzice de Bentinho. Sentia-se sufocada. A condução dos fatos que culminaram na traição, confirmada e justificada por essa Capitu, e os indicadores, no texto da aluna, giraram em torno dos fatos narrados no livro por Bentinho, distorcidos ao bel-prazer da aluna, que formou, assim, coerentemente, um quadro incontestável de traição. O texto me surpreendeu, tal foi a habilidade da aluna, que se valeu da carga psicológica que entranha o livro Dom Casmurro como matéria para tecer todas as artimanhas do seu texto. Uma outra surpresa foi com a personagem Sérgio, de Raul Pompeia, do livro O Ateneu. Toda opressão sentida pela personagem, frágil e sensível, foi retratada, melhor dizendo, interpretada pelo aluno. A visão de Sérgio daquela ambiência corrupta, que era o internato Ateneu, colégio em que estudara durante alguns anos, foi magistralmente composta no texto pelo aluno, que, num impulso, abandonou a leitura do texto e se aventurou a dramatizá-lo, de improviso, perante mim e os colegas. Chegou a fechar os punhos e bater na carteira como se estivesse em crise de desespero, num beco sem saída. O aluno extrapolou as recordações do Sérgio, de Raul Pompeia, narradas no livro, e invadiu - mundo interior da personagem, captado por ele, meu aluno, criando uma sequência de supostas impressões de Sérgio, 
desencadeadas pelo estado emocional da personagem. Conto isso com certa emoção, saudade e respeito, pela seriedade e autenticidade da apresentação. Momentos como esses foram ímpares na minha carreira de professora.

\section{Terceira Experiência - História de vida dos próprios alunos}

Como terceira experiência aqui relatada, uma atividade de Redação que também tinha um sentido diagnóstico para mim, no tocante ao conhecimento prévio a respeito dos alunos, sugeri que fizessem um retrospecto de sua vida escolar, pontuando cronologicamente os fatos narrados (sequência temporal, portanto), como marcos objetivos para que tivessem uma diretriz e não se perdessem no texto; entretanto o mais importante era a reflexão paralela sobre o processo de amadurecimento emanado dessas vivências. Solicitei que se esforçassem para identificar, de forma atemporal e subjetiva, esse amadurecimento, que tinha nos fatos (vivências) seu referencial de consultas. Sugeri que traduzissem, em palavras, os seus sentimentos impressos nos fatos vividos. Nesse sentido, para que respeitassem o próprio tempo psicológico, poderiam ter idas e vindas aos fatos antes narrados cronologicamente, e até sair do âmbito escolar. Este era apenas uma referência, um ponto de partida para a autoanálise.

Além do estudo de aspectos da narração, com essa atividade eu objetivava oportunizar-Ihes a reflexão sobre si próprios, a construção de diários, enfim, a organização do pensamento. Acrescento, ainda, como já dito, o intuito de conhecê-los. Seria um meio de olhá-los para compreendê-los melhor.

Também tinha o propósito de mostrar aos alunos que, quando se conhece o assunto, a dificuldade de escrever desaparece ou, pelo menos, é minimizada. Queria desmistificar o ato de escrever. Tratavase do meu primeiro ano com eles. Intencionava convencê-los de que todos somos capazes de escrever, principalmente quando conhecemos ou dominamos o que vamos expor. E no caso citado, o assunto era a própria vida deles.

Saíram textos surpreendentes. Grande parte das vezes, enormes. Um detalhe importante é que, antes de começarem a escrever, eu contava um pouco dos meus primeiros anos de escola, como a prepará-los para a escrita, aguçando as suas lembranças por meio das minhas. Minhas primeiras impressões da escola. Meus medos. A lembrança do cheiro da minha lancheira. O doce de abóbora com pão. A Nildona, que todos temiam. Minhas professoras queridas. Como deixaria de me lembrar da Dona Ana, minha primeira professora, com aqueles dois birotinhos na cabeça, separados por um 
traço tão certinho, que parecia ser feito com régua? O risquinho, que eu mirava, ia de ponta a ponta: começava na testa e terminava perto da nuca. Não tinha um fiozinho fora. Deitava o queixo na carteira, não escutava nem via mais nada, e ficava a admirar o penteado da professora, que não se alterava em nenhum dia do ano. Será que ela dorme com esses birotinhos?

E a Jane, minha vizinha e colega de carteira. Quase todo dia chorava, chorava. Um dia era o gato doente, outro dia o gato morreu, outro era a cisma de que era "de criação" (naquela época era a expressão que substituía o termo adotivo ou adotiva) ou que a mosca que pousou em seu lanche era a mesma que vira momentos antes no vaso sanitário... Cada dia, um drama. Eu gostava muito dela, era a minha melhor amiga, e não queria deixá-la só. Mas eu queria brincar e ela só queria chorar. E eu não a abandonava. Queria protegê-la. A Nildona aproveitava-se disso para comer o lanche da Jane. Certa vez também quis o meu. Ai de mim se não desse. Pior que era pão com doce de abóbora. Meu doce predileto! A abóbora era tirada do próprio quintal da minha casa.

Um dia a Nildona me chamou de "quatro olho", porque eu fui com os óculos de sol da minha mãe, modelo "gatinho". Eu estava com terçol. Chorei até...e ela foi parar na Diretoria.

E o choque do microfone! Terminei de recitar a poesia no primeiro degrau da escadinha do palco improvisado. Desci correndo, após o susto, o pulo e grito simultâneos. Que vergonha! A Nildona orquestrou uma risada entre os colegas. Foram dias e dias de ensaio em casa sob a orientação da minha mãe, que escolhera a poesia e me orientara na entoação. Tudo perdido com o choque.

Coitado do Toninho! Teve disenteria dentro da sala de aula. As carteiras eram fixas, com assento em ripas de madeira maciça, dispostamente vazadas, feitas para duas crianças se sentarem juntas. O seu colega levantou-se sem a mínima discrição, prendendo o nariz com os dedos polegar e indicador. O Toninho baixou a cabeça na carteira e não levantou mais. Durante muito tempo, até na rua ele evitava nos olhar.

Dona Vera! Como poderia me esquecer dela! Várias vezes a vi emocionar-se conosco. Ela continha o choro, mas o expressava no olhar lacrimejante e lábios trêmulos. Passava confiança, seriedade e afeto.

Também não poderia me esquecer do dia em que meu pai foi me buscar na escola. Estranhei a sua presença ali. Foi me buscar porque meu irmãozinho havia nascido. Eu estava no segundo ano do curso primário.

Certa vez meu pai chegou em casa com a coleção "Tesouro da criança". Devia conter, aproximadamente, dez livros, com capa dura 
vermelha e escritos dourados. Li e reli muitas vezes três livros. Na minha pouca idade, só me interessava pelos livros com ilustrações coloridas. As histórias que mais me fascinavam eram as que se desenrolavam na sala de aula do Mickey e sua turma. Aulas de Aritmética e de Leitura eram descritas e narradas em pormenores.

Os textos que eu lia viravam representações teatrais e brincadeiras de escolinha, que desenvolvíamos na varanda da minha casa, no interior paulista. Espaço não era problema.

Nessas representações, meu lobo mau, fruto da minha mente infantil, foi descoberto porque deixou o pijama cheio de pelos. A imaginação corria solta.

Meus pais me muniram de lousa e giz. A Marli era a minha aluna predileta. Com aqueles olhinhos de jaboticaba, sob a franja longa e lisa, olhava-me atenta. melhor?

Marli, deixa eu cortar sua franjinha para você enxergar Deixo, respondeu-me ela.

Peguei a tesoura sem que minha mãe visse e pus-me a aparar a franjinha.

O caminho de rato estava posto.

Minha irmã, dois anos mais velha do que eu, "sábia", "minha mestra", prontificou-se a acertar o cabelo, ou melhor, consertar o estrago. Acerta aqui, acerta ali, e a franja foi parar no topo da testa. Soubemos depois que a Marli ficou de castigo. Naquele dia o tempo fechou lá em casa. Eu e minha irmã também ficamos de castigo, além da bronca e do sermão.

Os alunos me escutavam atentos. Ora riam de minhas histórias, ora sorriam ou me interrompiam para contar uma passagem engraçada ocorrida com eles.

Enfim, antes da escrita dos textos eu os fazia mergulhar um pouco nesse universo da minha vivência. Tentava, por meio das palavras, fazer reviver no meu aluno os conteúdos psicológicos e afetivos que permeavam minha história.

Percebi a necessidade de, após minha narração, deixá-los à vontade para também mexerem em seus baús de lembranças, de forma que já fossem selecionando, naturalmente, os fatos a serem narrados e organizassem $o$ texto mentalmente. Contavam animadamente suas histórias. Um queria falar mais que o outro. Não notava que houvesse outro assunto ali, naquele momento, senão suas vidas.

Alguns escreveram muitas páginas; outros sugeriram colocar fotos. Eu os deixei livremente. A semente estava lançada. 
Esse trabalho, de certa forma, mesmo que inconscientemente para eles e para mim, convidava-os a perceber o processo de construção de sua identidade.

\section{Considerações Finais}

Revendo minhas vivências, diria que das representações teatrais no "cirquinho" (assim falávamos) que montávamos, a partir das histórias lidas, ficou a paixão pela Literatura, pelas personagens, reelaboradas com tantos detalhes; da "escolinha" do Mickey e sua turma retratada no livro que eu lia, incansavelmente, ficou a docência. Das minhas professoras ficou o referencial. Creio que saí daí. Meu destino estava traçado.

Hoje vejo que ali era possível perceber que o modelo de ensino impresso naquelas histórias era o mesmo sob o qual eu era educada. Dizendo de outra maneira, era aquele que eu vivia na escola e apreendia.

Nesse contato humano que passa em minha mente como numa galeria, percebo, a posteriori, que experimentei, em cada quadro, os primeiros indícios da construção em mim, em tenra idade, da compaixão, da solidariedade, da autodefesa, do companheirismo, da compreensão, do posicionamento frente a situações, do valor de expressar sentimentos, do valor do exemplo, do valor do afeto na aprendizagem, da responsabilidade para com os outros... Enfim, da identidade.

As minhas impressões sobre o mundo foram paulatinamente se transformando em conceitos que formulei, vistos e revistos ao longo da minha vida. Ainda os revejo, mas alguns se portam intocáveis, tal é a estrutura em que se solidificaram.

Em outras palavras, se assim podemos representar uma referência identitária, os primeiros quadros - estrutura basilar alicerçam quadros sobrepostos a determinarem novos aprendizados, novas apreensões. Porém as primeiras telas compõem a estrutura desses últimos. E a minha identidade foi e vai se consolidando em vários outros contextos, ou poderia dizer que a minha identidade estruturada ganhou novos contornos ante os vários contextos.

Onde estará o meu aluno Carlos, adolescente franzino, maduro para os seus quinze anos, que, em seu texto, durante essa terceira experiência de sala de aula, se referiu à sua mãe como "minha eterna asa protetora". Nunca me esqueci dessa sua expressão.

Como estará a Jane, minha amiga de infância? Que destino todos tomaram? Guardo-os com afeto. Até a Nildona! Ela era mais velha que todos da sala. Grande e forte. Era repetente. A palavra em si já carregava um estigma. Que motivações internas tinha para agir 
daquele jeito? Nesse seu histórico, provavelmente sob leituras equivocadas, consolidava-se uma identidade comprometida. Como a trataria, hoje, se eu fosse sua professora?

Talvez a tendência de buscar uma explicação para tudo, de querer saber o porquê das coisas, me levou à proposição de trabalhos, como os mencionados, que perseguissem os passos dos dados biográficos, quer fossem de escritores, quer fossem das personagens, quer fossem dos alunos. Buscava compreender 0 processo de construção da identidade, embora, na ocasião, não houvesse a intenção deliberada voltada para esse foco. A intenção primeira era observar para compreender. $E$ isso me fascinava.

Nestes dias em que referências, até então sólidas, estão em xeque, sofrendo novas composições, rearranjos, a exemplo da família, do trabalho, entre outras, faz-se mister incluir na programação da escola atividades que despertem o aluno para a reflexão sobre sua identidade. Ações pontuais que o ajudem a construí-la e a desvendá-la.

\section{Referências Bibliográficas}

FREIRE, Paulo; BETTO, Frei. Essa escola chamada vida: depoimentos ao repórter Ricardo Kotscho. 14. ed. São Paulo: Ática, 2003. (Série educação em ação).

Machado de Assis. Dom Casmurro. São Paulo: Saraiva, s.d. (Coleção jabuti)

NOVAES, Carlos Eduardo. O sonho do feijão. 18. ed. São Paulo: Ática, 2003. (Para gostar de ler, v. 7).

POMPEIA, Raul. O Ateneu. São Paulo: Abril Cultural, 1981. (Crônica de saudades). 